\title{
Phagocytized Silica Particles Cause IL-1 $\beta$ Release and Cell Death in Peritoneal Macrophages
}

\author{
Riyo Enomoto ${ }^{1,2}$, Hirofumi Tsuruda ${ }^{1}$, Kei Suzuki ${ }^{1}$, Yurika Endo ${ }^{1}$, Takuya Tsukamoto ${ }^{1}$ and Eibai Lee-Hiraiwa $a^{1,2^{\star}}$ \\ ${ }^{1}$ Laboratory of Pharmacology, Faculty of Pharmaceutical \\ Sciences, Kobe Gakuin University, Japan \\ ${ }^{2}$ Cooperative Research Center of Life Sciences, Kobe Gakuin \\ University, 1-1-3, Minatojima, Chuo-ku, Kobe 650-8586, Japan \\ *Corresponding author \\ Eibai Lee-Hiraiwa, Laboratory of Pharmacology, Faculty \\ of Pharmaceutical Sciences, Kobe Gakuin University 1-1-3 \\ Minatojima, Chuo-ku, Kobe 650-8586, Japan, Tel/Fax: +81-78- \\ 974-4681; E-mail: elee@pharm.kobegakuin.ac.jp
}

Submitted: 13 Oct 2016; Accepted: 21 Oct 2016; Published: 25 Oct 2016

\begin{abstract}
Objective: When cells are incubated with various particles in phagocytosis experiment, the cells include two populations. One is the population which engulfed the particles; the other is the population which did not engulf them. We separated both populations by use of a cell sorter and evaluated the cell death of the population which engulfed the particles to clarify the cytotoxic effect by the phagocytized particles in this study.

Methods and Results: Thioglycollate-elicited peritoneal macrophages engulfed $100 \mathrm{~nm}$ and $1000 \mathrm{~nm}$ of non-crystalline silica and polystyrene particles. Phagocytosis of these particles increased depending on the quantity of added particles. The treatment of the cells with $1000 \mathrm{~nm}$ silica particles induced release of lactate dehydrogenase $(L D H)$ and production of interleukin-1 $\beta$ (IL-1 $\beta$ ). On the other hand, $100 \mathrm{~nm}$ silica particles did not increase the LDH release and the IL-1 $\beta$ production. Polystyrene particles also did not have cytotoxic and inflammatory effects. To elucidate the relation of phagocytosis and cytotoxicity, the cells incubated with $1000 \mathrm{~nm}$ silica particles were divided into non-phagocytic and phagocytic population by use of a cell sorter. As most of dead cells stained by propidium iodide were observed in the phagocytic cells population, the phagocytosis of $1000 \mathrm{~nm}$ silica particle was associated with cell damage directly. The silica-induced cell death was not accompanied with the externalization of phosphatidylserine in the plasma membrane.

Conclusions: These results indicated the following things: (1) The engulfment of certain size of the silica particles induced cell death in the macrophages, (2) The cell death was not typical apoptosis and (3) The cell death was accompanied with the activation of inflammasome.
\end{abstract}

Keywords: Thioglycollate-elicited peritoneal macrophage, Silica particles, Phagocytosis, Cell death, IL-1 $\beta$, Inflammasome.

\section{Introduction}

Macrophages are one of the cells which bears central role in immune system and their major function is phagocytosis of various materials such as microbes, foreign particles and dead cells. These phagocytized materials are usually carried to the lysosome and adequately disposed by the lysosomal enzymes. Macrophages are known to engulf indigestible particles such as silica, asbestos and carbon. Silica is as multiple crystalline formsandnon-crystalline (amorphous) forms. Particularly, the crystalline silica particles are known to induce inflammation and cell death $[1,2]$. Chronic exposure to respilable crystalline silica particles leads to silicosis, a potentially lethal disease that is marked by inflammation and fibrosis of the lung. Resident alveolar macrophages normally play a protective role in the lung by cleaning foreign materials
$[3,4]$. However, scavenging of crystalline silica particles by the macrophages leads to direct release of inflammatory cytokines, which seems to be linked to development of silicosis $[5,6]$. Upon continuous exposure to crystalline silica, a decrease in the number of alveolar macrophages was observed in vivo [7]. In vitro studies have indicated that crystalline silica particles induce cell death in alveolar macrophages and macrophage cell lines [8-10].

A persistent overproduction of the pro-inflammatory cytokine interleukin-1 $\beta$ (IL-1 $\beta$ ) was observed in silicosis, and it seemed to act as a key inflammatory regulator $[11,12]$. Crystalline structure of particles such as silica, asbestos and alum has been reported to trigger the release of IL-1 $\beta$ from macrophages [13-17]. IL$1 \beta$ response is regulated by two separate mechanisms which are Toll-like receptors activation [18] and Nod-like receptors (NLRs) activation [19]. The latter is involved with the production of IL-1 $\beta$ by crystalline silica particles. Nod-like receptor family protein 3 
(NLRP3)constitutes Nod-like receptor family protein 3 (NLRP3) inflammasome with an adaptor protein and procaspase-1 [20].

Phagocytosis of crystalline or particulate structures triggers disintegration of endolysosomal organelles and the release of lysosomal contents into the cytosol. Crystalline or particulate structures are known to activate NLRP3 inflammasome via lysosomal rupture or production of reactive oxygen species (ROS) [13,15,21-24]. NLRP3 inflammasome is platforms for caspase-1 activation and mediates two caspase-1-dependent inflammatory processes: (1) Processing of IL-1 $\beta$ and IL-18 and (2) Inflammasome-dependent cell death called pyroptosis. Recent study has shown that not only crystalline silica particle but also on-crystalline silica particles increase IL- $1 \beta$ release via NLRP3 inflammasome.

Thus many findings have been reported about the association between phagocytosis of various crystalline and non-crystalline particles and the inflammasome activation. When cells are incubated with various particles in phagocytosis experiment, the cells include two populations. One is the population which engulfed the particles; the other is the population which did not engulf them. However, these populations were handled as one cell population treated with the particles, and both were not separately evaluated in previous studies. Therefore we separated both populations by use of a cell sorter and evaluated the cell death of the population which engulfed the particles to clarify the cytotoxic effect by the phagocytized particles in this study.

\section{Materials and Methods}

Ethics statement

This study was carried out in strict accordance with the recommendations in the Guide for the Care and Use of Laboratory Animals of the Ministry of Education, Culture, Sports, Science and Technology in Japan. The protocol including euthanasia method was approved by the Animal Research Committee of Kobe Gakuin University (Permit Number: A14-49). All surgery was performed under deep anesthesia, and all efforts were made to minimize suffering.

\section{Particles}

Sicastar ${ }^{\circledR g r e e n}-\mathrm{F}$ fluorescent silica particles were purchased from micromod Partikeltechnologie GmbH (Rostock, Germany). Fluoresbrite ${ }^{\circledR}$ yellow-green fluorescent polystyrene microspheres were purchased from Polysciences Inc. (Warrington, PA). All experiments were conducted with carboxylate-modified microspheres. The particles were sonicated by ultrasonic bath for 5 minutes before using.

\section{Macrophage preparation}

Male ddY mice (7-8 week-old) were purchased from Japan SLC, Inc. (Shizuoka, Japan). Thioglycollate-elicited peritoneal macrophages from ddY mice were obtained by the peritoneal lavage technique. Four days after peritoneal injection of 3\% $\mathrm{w} / \mathrm{v}$ thioglycolate medium $(0.1 \mathrm{ml} / \mathrm{g}$ mice $)$, mice were ethically sacrificed by deep anesthesia. The lower abdominal area was incised small, and $4 \mathrm{ml}$ of cold phosphate buffed saline (PBS) was injected into the peritoneal cavity with Pasteur pipette. The wound was clipped with forceps and the abdomen was raised and shaken to wash the peritoneal cavity. Pasteur pipette was inserted into the upper part of the abdomen and peritoneal fluids were collected. Above handling was repeated three times. The resultant cell suspension was centrifuged at $350 \times \mathrm{g}$ for 5 minutes and then the cells were treated with hypotonic saline solution to burst erythrocytes. This cell suspension was centrifuged at $350 \times \mathrm{g}$ for 5 minutes and the cell pellet was resuspended with RPMI-1640 (Nacalai Tesque, Kyoto, Japan) including 5\% decomplemented fetal bovine serum (FBS, GIBCO ${ }^{2} /$ Life Technologies, Carlsbad, $\mathrm{CA})$. The cells were seeded in 8 -well chambers $\left(0.8 \mathrm{~cm}^{2}, 1.5 \times 10^{5}\right.$ cells/well) for morphological observation, 24-well plates $\left(1.9 \mathrm{~cm}^{2}\right.$, $3.0 \times 10^{5}$ cells/well) for flow cytometry analysis, 96-well plates $\left(0.32 \mathrm{~cm}^{2}, 7.0 \times 10^{4}\right.$ cells/well $)$ for ROS measurement and $60 \mathrm{~mm}$ dishes $\left(20 \mathrm{~cm}^{2}, 4 \times 10^{6} \mathrm{cells} / \mathrm{dish}\right)$ for cell sorting. The cells were incubated at $37^{\circ} \mathrm{C}$ and $5 \% \mathrm{CO}_{2}$. After 1 hour, the cells were washed to separate out any non-adhesive cells.

The next day, the cells were used various experiments. Macrophage purity was immunologically determined by flowcytometry analysis and morphological observation using the specific markers of macrophages such as CD68 and F4/80.

\section{Morphological observation of phagocytosis}

The particles were suspended in RPMI 1640 medium with $1 \%$ bovine serum albumin (BSA). BSA was added to dispersant to prevent adsorption to the vessels. BSA had no effect on phagocytosis of particles (data not shown). Various concentrations of the particle suspensions were prepared. The particle suspensions were sonicated by ultrasonic bath for 5 minutes before using and applied to the cells for 24 hours. At the end of the incubation period, cells were washed twice with phosphate buffered saline and observed by a laser-scanning microscope (FV1000-D, Olympus Corporation, Tokyo, Japan).

\section{LDH and IL-1 $\beta$ measurement}

To evaluate cell damage, lactate dehydrogenase (LDH) leakage from the cells was measured. The culture supernatants were collected after the incubation with the particles. The supernatants were centrifuged at $750 \times \mathrm{g}$ for 10 minutes and applied to LDHCytotoxic Test Wako (Wako Pure Chemical Industries, Ltd., Osaka, Japan). The release of interleukin-1 $\beta$ (IL-1 $\beta$ ), an inflammatory cytokine, was determined by use of Mouse IL-1 beta/IL-1F2 Quantikine ELISA Kit (R\&D systems, Inc., Minneapolis, MN).

\section{ROS measurement}

To determine reactive oxygen species (ROS) production in the cells, the culture supernatants were removed after the incubation with the particles. CellROX ${ }^{\circledR}$ Green reagent (Molecular Probes/ Life Technologies, Carlsbad CA) were added to the cells. The cells were incubated at $37^{\circ} \mathrm{C}$ for 30 minutes and then washed twice with PBS. The fluorescence was measured by micro plate spectrofluorometer (Gemini EM, Molecular Devices, Sunnyvale, CA). 
Cell sorting

The particles were suspended in RPMI 1640 medium with 1\% BSA. BSA was added to dispersant to prevent adsorption to the vessels. BSA had no effect on phagocytosis of particles (data not shown). The particle suspensions were sonicated by ultrasonic bath for 5 minutes before using. Peritoneal macrophages were incubated with $1000 \mathrm{~nm}$ silica particles (100 particles/cell) for 1 hour. After the incubation, the cells were washed twice with PBS and to remove free particles and harvested by trypsinization. The harvested cells were suspended in PBS and analyzed and separated by cell sorter (FACSAria, BD Biosciences, Franklin Lakes, NJ). The cells were sorted by non-phagocytic and phagocytic populations and then the sorted cells were re-cultured in RPMI 1640 medium including 5\% FBS for 12 or 24 hours.

\section{Morphological observation}

The $1000 \mathrm{~nm}$ silica particle suspensions were applied to the cells in the 8-well chambers for indicated times. After the incubation, the cells were washed twice with PBS to remove free particles. The cells were stained to evaluate cell death by propidium iodide (PI) or Annexin V conjugated Alexa 647 (Molecular Probes/Life Technologies, Carlsbad CA) and observed by a laser-scanning confocal microscope.

\section{Results}

Characterization of thioglycollate-elicited peritoneal macrophages Peritoneal macrophages from ddY mouse were immunologically stained by using the macrophage specific markers such as CD68 and F4/80. The cells were applied to quantitative analysis and morphological observation. As indicated in figure 1, the mean percentages of CD68- positive and F4/80- positive cells were $90.48 \pm 0.15$ and $93.26 \pm 0.14$, respectively.
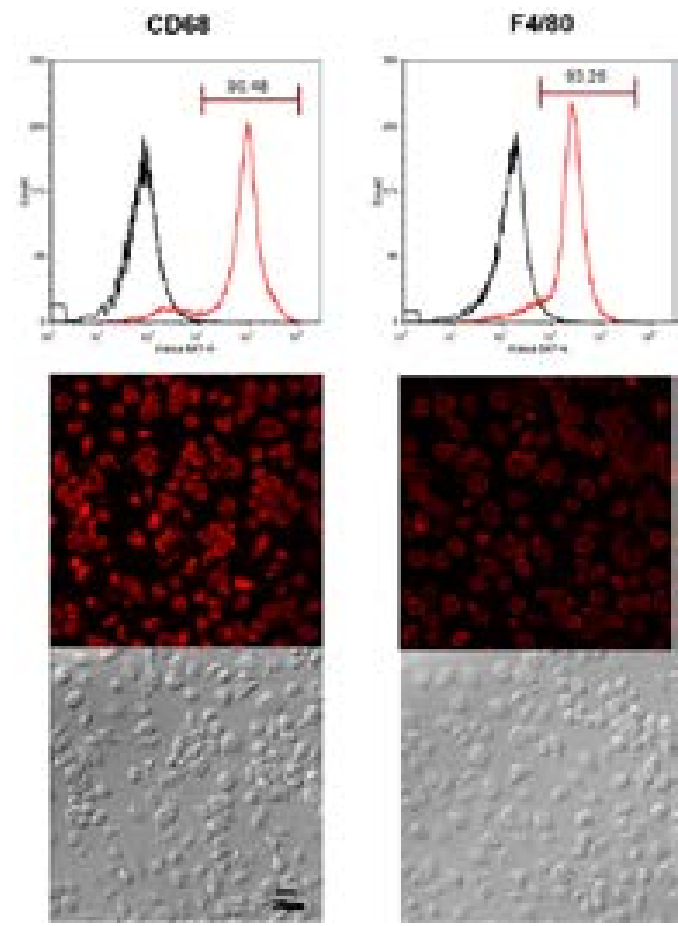

Figure 1: Characterization of macrophages from mouse.
Cells were harvested by trypsinization and immunologically stained by use of anti-mouse CD68 antibody and anti-mouse F4/80 antibody. The stained cells were analyzed by flow cytometory. The cells which stained by use of the specific antibodies were indicated by red lines and the cells which added only fluorescent secondary antibody were indicated by black lines (upper panel).

Cells seeded in the glass bottom chamber were immunologically stained by use of anti-mouse CD68 antibody and anti-mouse F4/80 antibody and then observed by a laser-scanning confocal microscope (lower panel). Bar, $20 \mu \mathrm{m}$.

\section{Morphological observation of phagocytosis}

Cells were incubated with $100 \mathrm{~nm}$ and $1000 \mathrm{~nm}$ of fluorescent particles for 24 hours. Peritoneal macrophages phagocytized both sizes of non-crystalline silica and polystyrene particles (Figure 2). Phagocytosis of these particles increased according to the additive amount of the particles (data not shown).

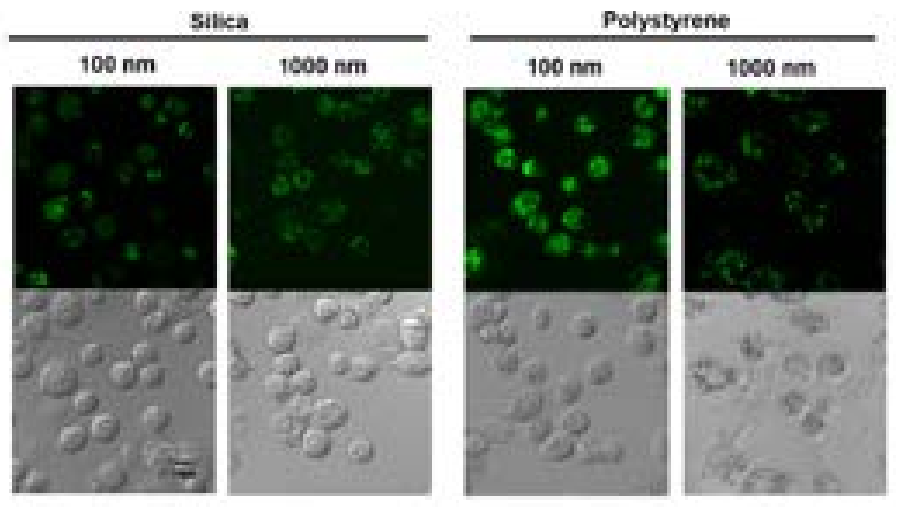

Figure 2: Phagocytosis of silica and polystyrene particles by peritoneal macrophages.

Cells seeded in the glass bottom chamber were incubated with $100 \mathrm{~nm}$ (100000 particles/cell) or $1000 \mathrm{~nm}$ (100 particles/ cell) of fluorescent particles for 24 hours. After the incubation, the cells were washed 2 times and observed by a laser-scanning confocal microscope. Bar $10 \mu \mathrm{m}$.

Measurement of LDH leakage and ROS and IL-1 $\beta$ production To evaluate whether the phagocytized particles cause cell damage or not, we measured LDH leakage from the cells to culture supernatants. Peritoneal macrophages were incubated with 1000 $\mathrm{nm}$ silica and polystyrene particles for 24 hours (Figure 3a).

Phagocytosis of $1000 \mathrm{~nm}$ silica particles induced cell damage depending on the amount of particles. Meanwhile, LDH leakage was not detected in the cells incubated with $1000 \mathrm{~nm}$ polystyrene particles.

We also performed the same examination using $100 \mathrm{~nm}$ silica particles. The small particles did not show the cytotoxicity regardless of quantity of the addition (Figure 3b). 

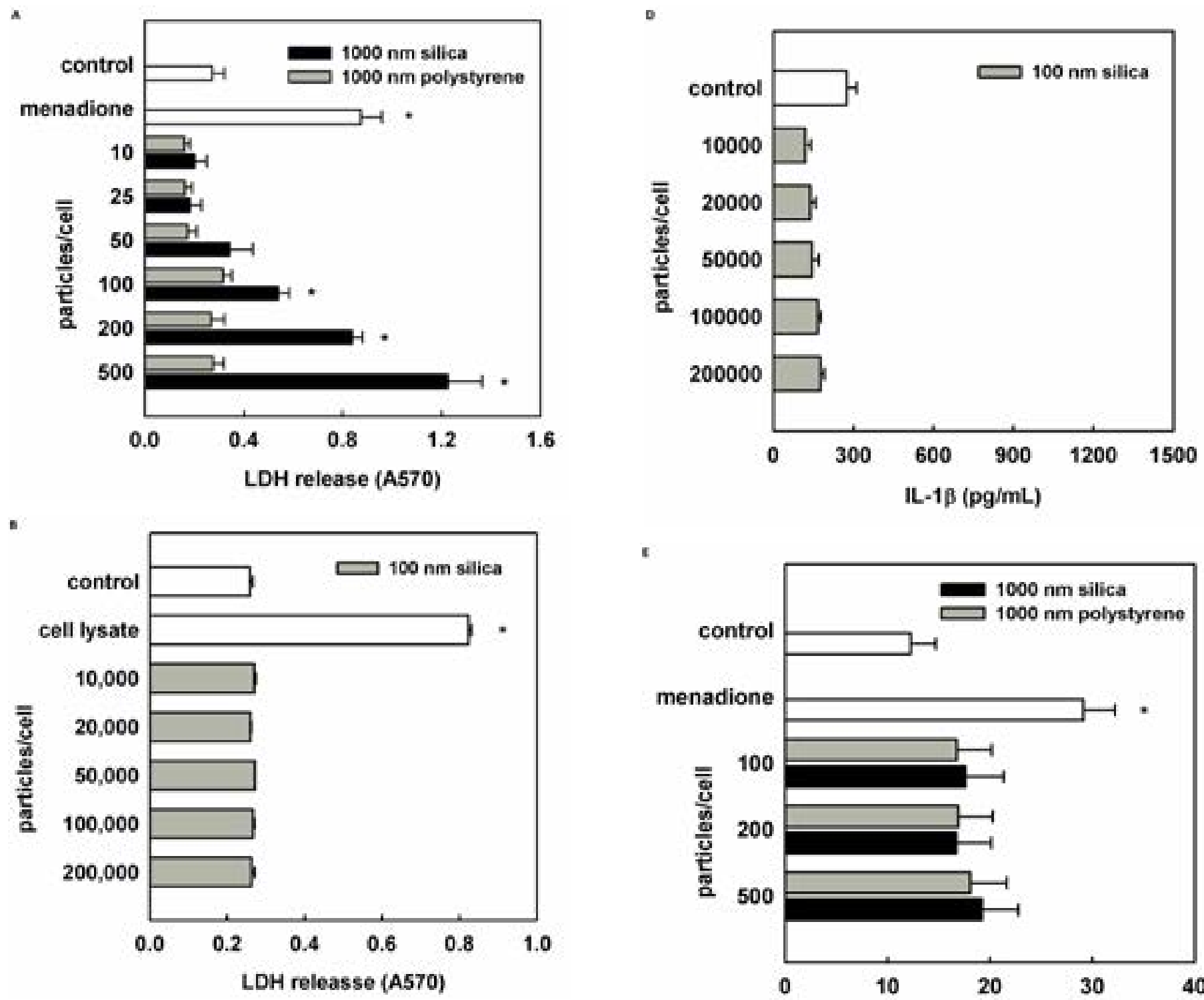

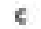
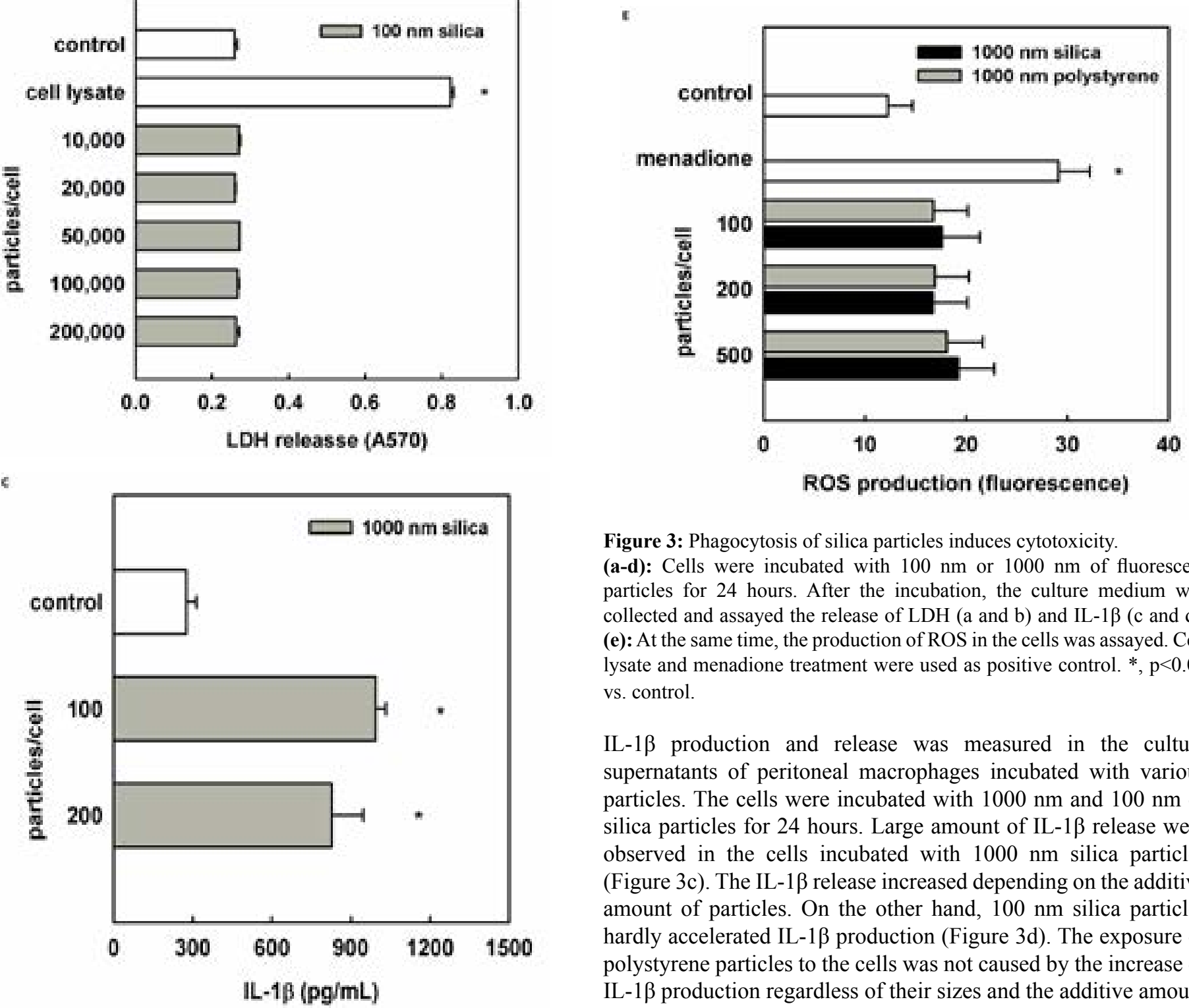

Figure 3: Phagocytosis of silica particles induces cytotoxicity. (a-d): Cells were incubated with $100 \mathrm{~nm}$ or $1000 \mathrm{~nm}$ of fluorescent particles for 24 hours. After the incubation, the culture medium was collected and assayed the release of LDH ( $a$ and b) and IL-1 $\beta$ (c and d). (e): At the same time, the production of ROS in the cells was assayed. Cell lysate and menadione treatment were used as positive control. ${ }^{*}, \mathrm{p}<0.05$ vs. control.

IL-1 $\beta$ production and release was measured in the culture supernatants of peritoneal macrophages incubated with various particles. The cells were incubated with $1000 \mathrm{~nm}$ and $100 \mathrm{~nm}$ of silica particles for 24 hours. Large amount of IL-1 $\beta$ release were observed in the cells incubated with $1000 \mathrm{~nm}$ silica particles (Figure $3 \mathrm{c}$ ). The IL-1 $\beta$ release increased depending on the additive amount of particles. On the other hand, $100 \mathrm{~nm}$ silica particles hardly accelerated IL-1 $\beta$ production (Figure $3 \mathrm{~d}$ ). The exposure of polystyrene particles to the cells was not caused by the increase of IL- $1 \beta$ production regardless of their sizes and the additive amount 
(data not shown). To determine ROS production, peritoneal macrophages were incubated with various amounts of $1000 \mathrm{~nm}$ silica and polystyrene particles for 3 hours. Phagocytosis of the particles did not affect ROS production regardless of their base materials and the additive amount (Figure 3e).

\section{Cell sorting}

Peritoneal macrophages were incubated with $1000 \mathrm{~nm}$ silica particles for 1 hour and then sorted by the amount of phagocytized particles. We defined the cells which engulfed large amount of the particles as the phagocytic population, and non-phagocytic population and phagocytic population were separately collected (Figure 4a). These cells were re-cultured in culture medium without the particles. After 24 hours later, PI-positive dead cells were increased in the cells collected as phagocytic cells (Figure 4b). The percentage of PI-positive cells in the cells which were collected as non-phagocyte population was equal to control macrophages (Figure 4c). To evaluate whether this cell death is apoptosis or not, we examined externalization of phosphatidylserine in plasma membrane. The non-phagocytic and phagocytic cells were stained by annexin V conjugated with Alexa 647. Many annexin V-positive cells were found in the phagocytic population, but circular staining of plasma membrane which is one of the features of apoptotic cell death was hardly observed (Figure 4d).
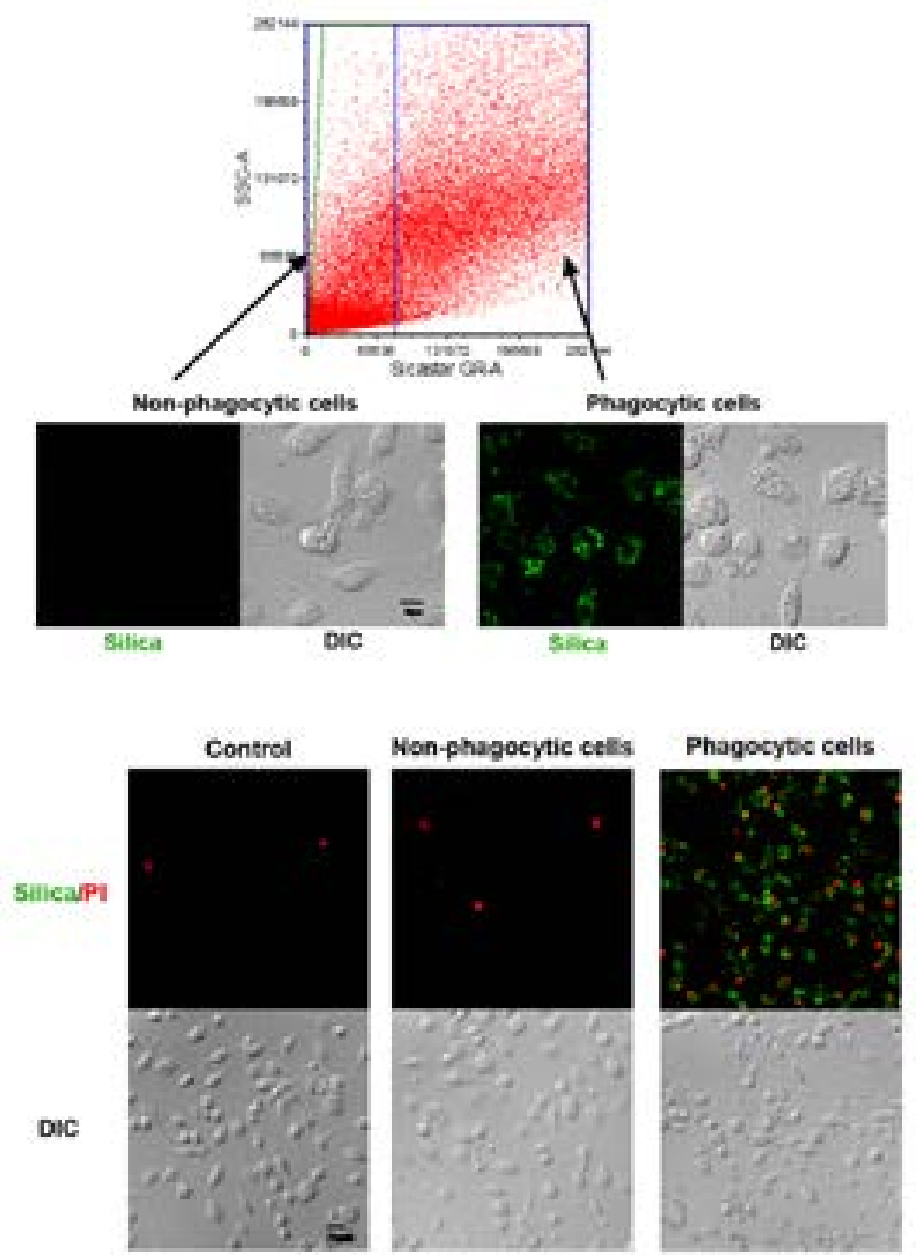
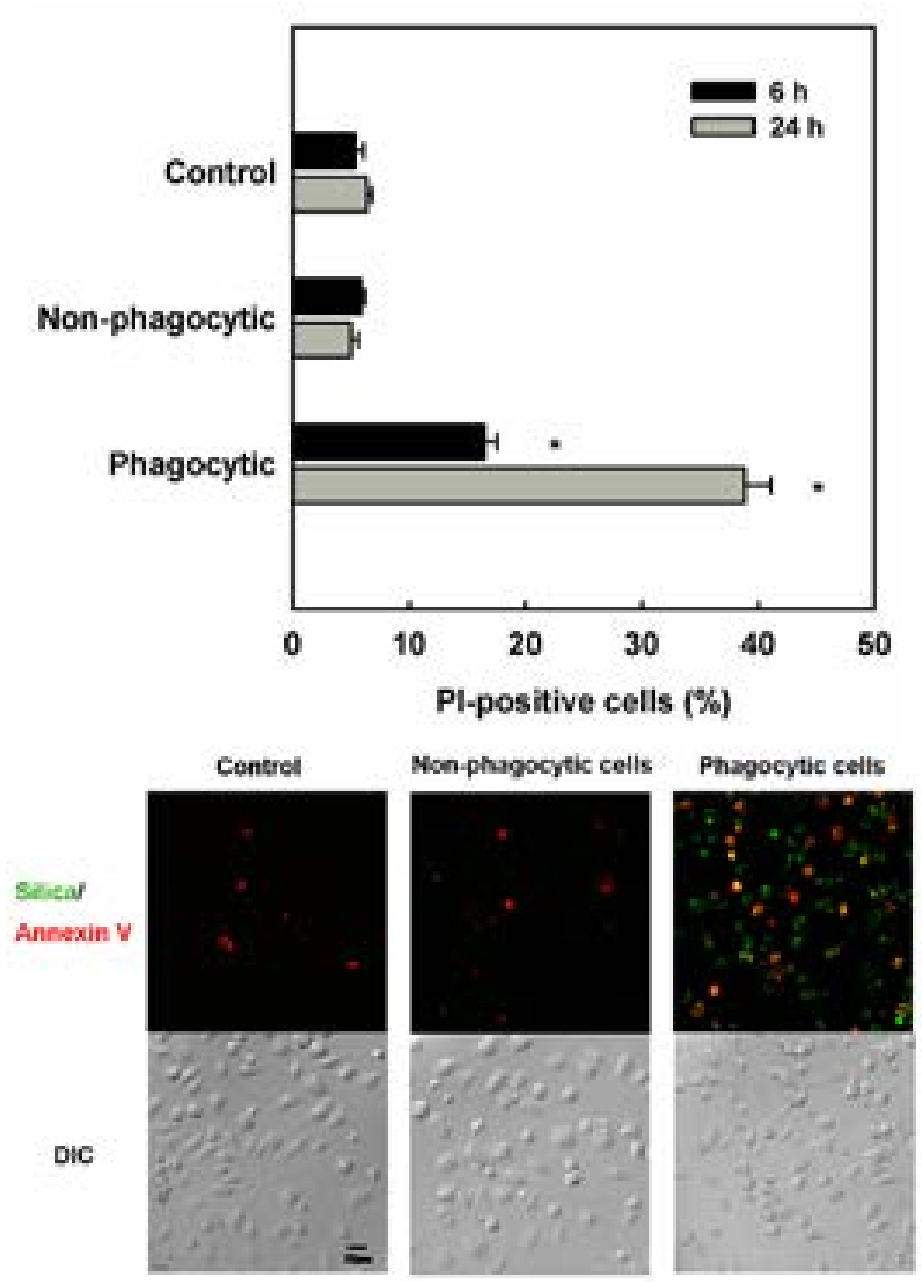

Figure 4: Phagocytosis of silica particles induces cell death of peritoneal macrophages.

(a): Cells were incubated with $1000 \mathrm{~nm}$ fluorescent silica particles (100 particles/ cell) for 1 hour. After the incubation, the cells were harvested by trypsinization and two populations were sorted by a cell sorter. These populations were re-seeded in the glass bottom chamber and cultured for 24 hours. The cells were observed by a laser-scanning confocal microscope. Bar, $10 \mu \mathrm{m}$. (b and c): The cells re-seeded in glass bottom chamber were stained by PI and observed bya laser-scanning confocal microscope. Bar, $20 \mu \mathrm{m}$. PI-positive cells were counted in four images and the percentages were calculated. (d) The cells re-seeded in glass bottom chamber were stained by Annexin V conjugated Alexa 647 and observed by alaser-scanning confocal microscope. Bar $20 \mu \mathrm{m}$.

\section{Discussion}

Phagocytosis of $1000 \mathrm{~nm}$ non-crystalline silica particles induced cell death of peritoneal macrophages. In this study, we tried to separate the phagocytic cell population and to evaluate the cytotoxicity of them. Although cells were incubated with the silica particles for 1 hour, dead cells were hardly present in the nonphagocytic population. The cell death was not induced only by the transient contact with the particles. This result indicated that the engulfment of the particles triggered the cell death.

The cytotoxicity of the particles seemed to be involved in the base materials and particle sizes. Since phagocytized particles occupy 
the space in the cells, we estimated that total surface area or total volume of added particles participate in the cytotoxicity of silica particles. Consequently, $100 \mathrm{~nm}$ silica particles were added to the cells at the same total surface (20000 particles/cell, $200 \pi \mu \mathrm{m}^{2} /$ cell) area and same total volume (200000 particles/cell, $33.4 \pi \mu \mathrm{m}^{3} /$ cell) with $1000 \mathrm{~nm}$ particles (200 particles/cell, $200 \pi \mu \mathrm{m}^{2} /$ cell, 33.4 $\pi \mu \mathrm{m}^{3} /$ cell). The particles were taken into the cells depending on the additive amount. On the other hand, $100 \mathrm{~nm}$ silica particles hardly had cytotoxic effect regardless of its amount. These results indicated that the cytotoxicity of silica particles had no relevance to the total surface area and the total volume of added particles. In previous studies, the inflammatory effect of carbon nano particles depended on the surface area of the particle [25,26]. The small particles that surface area per weight was big showed strong inflammation in this study. However, we were not able to find the relation between the surface area and the cytotoxicity. The polystyrene particles had no effect on LDH release and IL-1 $\beta$ production regardless of their sizes or amounts. In consequence, the occupation of the inner space in the cells with indigestible particles does not seem to be a direct cause of cytotoxicity.

Generally cell death is classified as either apoptosis or necrosis. Apoptosis is described as a programmed process of autonomous cellular dismantling that avoids eliciting inflammation. Necrosis has been characterized as accidental cell death resulting from environmental perturbations with uncontrolled release of inflammatory cellular contents [27]. After the incubation of the cells with $1000 \mathrm{~nm}$ silica particles, annexin V-positive cells increased but typical externalization of phosphatidylserine was not observed in the phagocytic population. Internalization of annexin $\mathrm{V}$ by the plasma membrane rupture was suspected. Moreover, the cytotoxicity of $1000 \mathrm{~nm}$ silica particles was accompanied with the release of IL-1 $\beta$. The level of cytotoxicity by the silica particles correlated with the release of IL-1 $\beta$. IL- $1 \beta$ is one of the proinflammatory cytokines and produced from proIL-1 $\beta$ by caspase-1 [28]. Caspase-1 is one of the proinflammatory caspases and it exists as pro-caspase-1 which is inactive form in cytosol. Pro-caspase-1 is a component of inflammasome. Inflammasome is a multi-protein complex of over $700 \mathrm{kDa}$ that is responsible for the activation of the caspase- 1 which is essential for pro IL$1 \beta$ processing and mature IL-1 $\beta$ secretion. The formation of inflammasome induces assembly of pro-caspase-1 via adaptor molecule and activation of caspase- 1 by self-digestion [20]. Since the silica particles-induced cell death was accompanied with the release of IL-1 $\beta$, this cell death seemed to be dependent on caspase-1 activation. These results suggest that $1000 \mathrm{~nm}$ silica particles induce pyroptosis which is inflammasome-dependent cell death.

NLRP3 is one of NLR family proteins and a constituent of NLRP3 inflammasome NLRP3 inflammasome is the most studied inflammasomes [20]. NLRP3 inflammasome was activated by various inducers, for example, ingredients derived from microbes dsDNAand ATP which are released by damaged cells and particulate chemical materials such as asbestos and silica [1,13,15,29-33]. Crystal-dependent NLRP3 inflammasome activation is known to go through ROS-dependent or cathepsin B-dependent pathway [20]. Phagocytosis of crystalline or particulate structure leads to lysosomal damage, resulting in cytosolic release of lysosomal contents such as cathepsins [16]. The lysosomal protease was reported to activate NLRP3 inflammasome directly. In this study, we examined cytotoxicity of macrophages following phagocytosis of $100 \mathrm{~nm}$ and $1000 \mathrm{~nm}$ of silica or polystyrene particles. Phagocytosis of only $1000 \mathrm{~nm}$ silica particles induced release of LDH and IL-1 $\beta$. Production of ROS was not detected in the cells which phagocytized polystyrene and silica particles. These results suggest that phagocytosis of $1000 \mathrm{~nm}$ silica particles leads to activation of NLRP3 inflammasome following lysosomal damage. The size of silica particle or base materials of particles may be involved with lysosomal damage by engulfment of them. The cell death induced by $1000 \mathrm{~nm}$ silica particles did not show typical characteristic of apoptosis such as phosphatidylserine externalization and was accompanied with release of IL-1 $\beta$. Our results suggest that the certain size of silica particles induce the activation of inflammasome and pyroptosis.

\section{Authour's contribution}

Dr. Lee-Hiraiwa and Dr. Enomoto designed the study. Dr. Enomoto wrote the protocol and interpreted the data. Mr. Tsuruda planned and performed the cell sorting and the morphological studies. Ms. Suzuki and Ms. Endo carried out the cytotoxicityand cytokine measurement. Mr. Tsukamoto carried out the cell sorting. All authors read and approved the final manuscript.

\section{Acknowledgments}

This work was supported by the MEXT-Supported Program for the Strategic Research Foundation at Private Universities, 2012-2017.

\section{Refrences}

1. Peeters PM, Perkins TN, Wouters EF, Mossman BT, Reynaert NL (2013) Silica induces NLRP3 inflammasome activation in human lung epithelial cells. Part Fibre Toxicol 10: 3 .

2. Joshi GN, Knecht DA (2013) Silica phagocytosis causes apoptosis and necrosis by different temporal and molecular pathways in alveolar macrophages. Apoptosis 18: 271-285.

3. Dauber JH, Rossman MD, Pietra GG, Jimenez SA, Daniele RP (1980) Experimental silicosis: morphologic and biochemical abnormalities produced by intratracheal instillation of quartz into guinea pig lungs. Am J Pathol 101: 595-612.

4. Gardner DE (1984) Alterations in macrophage functions by environmental chemicals. Environ Health Perspect 55: 343 358.

5. Huaux F (2007) New developments in the understanding of immunology in silicosis. Curr Opin Allergy Clin Immunol 7: 168-173.

6. Mossman BT, Churg A(1998) Mechanisms in the pathogenesis of asbestosis and silicosis. Am J Respir Crit Care Med 157: 1666-1680.

7. Borges VM, Falcão H, Leite-Júnior JH, Alvim L, Teixeira GP, et al. (2001) Fas ligand triggers pulmonary silicosis. J Exp Med 194: 155-164.

8. Hu S, Zhao H, Al-Humadi NH, Yin XJ, Ma JK (2006) Silica- 
induced apoptosis in alveolar macrophages: evidence of in vivo thiol depletion and the activation of mitochondrial pathway. J Toxicol Environ Health A 69: 1261-1284.

9. Thibodeau M, Giardina C, Hubbard AK (2003) Silicainduced caspase activation in mouse alveolar macrophages is dependent upon mitochondrial integrity and aspartic proteolysis. Toxicol Sci 76: 91-101.

10. Thibodeau MS, Giardina C, Knecht DA, Helble J, Hubbard AK (2004) Silica-induced apoptosis in mouse alveolar macrophages is initiated by lysosomal enzyme activity. Toxicol Sci 80: 34-48.

11. Piguet PF, Vesin C, Grau GE, Thompson RC (1993) Interleukin 1 receptor antagonist (IL-1ra) prevents or cures pulmonary fibrosis elicited in mice by bleomycin or silica. Cytokine 5: 57-61.

12. Srivastava KD, Rom WN, Jagirdar J, Yie TA, Gordon T, et al. (2002) Crucial role of interleukin-1beta and nitric oxide synthase in silica-induced inflammation and apoptosis in mice. Am J Respir Crit Care Med 165: 527-533.

13. Dostert C, Pétrilli V, Van Bruggen R, Steele C, Mossman BT, et al. (2008) Innate immune activation through Nalp3 inflammasome sensing of asbestos and silica. Science 320: 674-677.

14. Duewell P, Kono H, Rayner KJ, Sirois CM, Vladimer G, et al. (2010) NLRP3 inflammasomes are required for atherogenesis and activated by cholesterol crystals. Nature 464: 1357-1361.

15. Hornung V, Bauernfeind F, Halle A, Samstad EO, Kono H, et al. (2008) Silica crystals and aluminum salts activate the NALP3 inflammasome through phagosomal destabilization. Nat Immunol 9: 847-856.

16. Cassel SL, Eisenbarth SC, Iyer SS, Sadler JJ, Colegio OR, et al. (2008) The Nalp3 inflammasome is essential for the development of silicosis. Proc Natl Acad Sci U S A 105: $9035-$ 9040.

17. Eisenbarth SC, Colegio OR, O'Connor W, Sutterwala FS, Flavell RA (2008) Crucial role for the Nalp3 inflammasome in the immunostimulatory properties of aluminium adjuvants. Nature 453: 1122-1126.

18. Kawai T, Akira S (2011) Toll-like receptors and their crosstalk with other innate receptors in infection and immunity. Immunity 34: 637-650.

19. Martinon F, Mayor A, Tschopp J (2009) The inflammasomes: guardians of the body. Annu Rev Immunol 27: 229-265.

20. Schroder K, Tschopp J (2010) The inflammasomes. Cell 140: 821-832.

21. Lima H Jr, Jacobson LS, Goldberg MF, Chandran K, DiazGriffero F, et al. (2013) Role of lysosome rupture in controlling Nlrp3 signaling and necrotic cell death. Cell Cycle 12: 18681878.
22. Fubini B, Hubbard A (2003) Reactive oxygen species (ROS) and reactive nitrogen species (RNS) generation by silica in inflammation and fibrosis. Free Radic Biol Med 34: 15071516.

23. Morishige T, Yoshioka Y, Inakura H, Tanabe A, Yao X, et al. (2010) The effect of surface modification of amorphous silica particles on NLRP3 inflammasome mediated ILlbeta production, ROS production and endosomal rupture. Biomaterials 31: 6833-6842.

24. Winter M, Beer HD, Hornung V, Krämer U, Schins RP, et al. (2011) Activation of the inflammasome by amorphous silica and $\mathrm{TiO} 2$ nanoparticles in murine dendritic cells. Nanotoxicology 5: 326-340.

25. Reisetter AC, Stebounova LV, Baltrusaitis J, Powers L, Gupta A, et al. (2011) Induction of inflammasome-dependent pyroptosis by carbon black nanoparticles. J Biol Chem 286: 21844-21852.

26. Stoeger T, Reinhard C, Takenaka S, Schroeppel A, Karg E, et al. (2006) Instillation of six different ultrafine carbon particles indicates a surface area threshold dose for acute lung inflammation in mice. Environ Health Perspect 114: 328-333.

27. Fink SL, Cookson BT (2005) Apoptosis, pyroptosis, and necrosis: mechanistic description of dead and dying eukaryotic cells. Infect Immun 73: 1907-1916.

28. Martinon F, Burns K, Tschopp J (2002) The inflammasome: a molecular platform triggering activation of inflammatory caspases and processing of proIL-beta. Mol Cell 10: 417-426.

29. Holzinger D, Gieldon L, Mysore V, Nippe N, Taxman DJ, et al. (2012) Staphylococcus aureus Panton-Valentine leukocidin induces an inflammatory response in human phagocytes via the NLRP3 inflammasome. J Leukoc Biol 92: 1069-1081.

30. Busso N, So A (2012) Microcrystals as DAMPs and their role in joint inflammation. Rheumatology (Oxford) 51: 1154-1160.

31. Edye ME, Lopez-Castejon G, Allan SM, Brough D (2013) Acidosis drives damage-associated molecular pattern (DAMP)-induced interleukin-1 secretion via a caspase-1independent pathway. J Biol Chem 288: 30485-30494.

32. Gombault A, Baron L, Couillin I (2013) ATP release and purinergic signaling in NLRP3 inflammasome activation. Front Immunol 3: 414.

33. Riteau N, Baron L, Villeret B, Guillou N, Savigny F, et al. (2012) ATP release and purinergic signaling: a common pathway for particle-mediated inflammasome activation. Cell Death Dis 3: e403.
Copyright: (02016 Lee-Hiraiwa E, et al. This is an open-access article distributed under the terms of the Creative Commons Attribution License, which permits unrestricted use, distribution, and reproduction in any medium, provided the original author and source are credited. 